\title{
Valoração de serviços ecossistêmicos em uma bacia de abastecimento na Rota de Integração Latino-Americana
}

\author{
Valuation of ecosystem services in a supply basin on the Latin American \\ Integration Route
}

\section{Valoración de servicios ecosistémicos en una cuenca de abastecimiento en la Ruta de Integración Latinoamericana}

\author{
Wesley dos Santos Carvalho ${ }^{1}$ \\ Monik Loraine Candido Cunha ${ }^{1}$ \\ Izabella do Carmo Amaral ${ }^{1}$ \\ Fernando Jorge Corrêa Magalhães Filho ${ }^{1}$
}

Recebido em: 04/05/2020; revisado e aprovado em: 16/07/2020; aceito em: 17/09/2020

DOI: http://dx.doi.org/10.20435/inter.v22i3.3041

\begin{abstract}
Resumo: O estudo valorou os serviços ecossistêmicos prestados pela bacia do rio Santo Antônio, localizada em Guia Lopes da Laguna (MS), utilizando dados da dinâmica do uso e ocupação do solo entre os anos de 2009 e 2019. Os resultados demonstraram que o valor dos serviços ecossistêmicos prestados pelas classes de uso de solo estudadas representou um fluxo anual de, aproximadamente, US\$ 93,8 milhões em serviços ecossistêmicos no ano de 2019. Entretanto, comparando-se os anos de 2009 a 2019, observou-se uma redução de $26,44 \%$ no fluxo anual dos serviços ecossistêmicos, devido, principalmente, à redução das áreas de vegetação nativa na bacia.
\end{abstract}

Palavras-chave: serviços ecossistêmicos; valoração ambiental; uso e ocupação do solo.

Abstract: The study valued the ecosystem services provided by the rio Santo Antônio basin, located in Guia Lopes da Laguna (MS), using data from the dynamics of land use and occupation between the years 2009 to 2019. The results showed that the value of ecosystem services provided by the classes of land use studied represented an annual flow of approximately US\$ 93.8 million in ecosystem services in 2019. However, comparing the years from 2009 to 2019 , a reduction of $26.44 \%$ was observed in the annual flow of ecosystem services, mainly due to native vegetation areas reduction in the basin.

Keywords: ecosystem services; environmental valuation; land use and occupation.

Resumen: El estudio valoró los servicios ecosistémicos proporcionados por la cuenca del Río Santo Antônio, ubicada en Guia Lopes da Laguna (MS), utilizando datos de la dinámica del uso y la ocupación de la tierra entre los años 2009 y 2019. Los resultados mostraron que el valor de los servicios ecosistémicos proporcionados por las clases de uso de la tierra estudiadas representó un flujo anual de, aproximadamente, US\$ 93,8 millones en servicios ecosistémicos en 2019. Sin embargo, al comparar los años 2009 a 2019, se observó una reducción del 26,44\% en el flujo anual de servicios ecosistémicos, principalmente, debido a la reducción de áreas de vegetación nativa en la cuenca.

Palabras clave: servicios ecosistémicos; valoración ambiental; uso del suelo y ocupación.

\section{INTRODUÇÃO}

\subsection{A questão de valoração ambiental}

Ainda é presente a ideia de que os recursos naturais são ilimitados, o que leva à percepção de que eles nunca se esgotam. Nesta visão, o valor atribuído aos recursos naturais poderia ser considerado como zero ou infinito, sendo encarados, desta maneira, como "bens gratuitos".

Os sistemas financeiros tradicionais não consideram estes recursos em sua contabilidade econômica, embora sejam explorados na produção de bens e serviços (MANGABEIRA; TÔSTO;

\footnotetext{
${ }^{1}$ Universidade Católica Dom Bosco (UCDB), Campo Grande, Mato Grosso do Sul, Brasil.
} 
ROMEIRO, 2011; ANDRADE et al., 2012). Andrade (2008) explica que a economia tradicional interage com o ambiente na forma de impactos. O resultado dessa interação se resume em extrair recursos naturais e devolver subprodutos, geralmente atrelado aos resíduos.

O entendimento do funcionamento dos ecossistemas e as interações entre economia e ecologia permitem estabelecer importantes instrumentos para a preservação e proteção ambiental e a aceitação social da necessidade da gestão racional dos ambientes naturais (CUNHA, 2008).

De acordo com Tôsto (2010), o desenvolvimento econômico e o meio ambiente estão indissoluvelmente vinculados. Portanto, é fundamental que as teorias econômicas considerem em seu arcabouço teórico as complexas interações dos sistemas econômicos e o meio ambiente natural (ANDRADE, 2008).

Desta maneira, o meio ambiente fornece benefícios diretos e indiretos ao ser humano na forma de serviços ecossistêmicos. Estes serviços dão suporte às funções que garantem a sobrevivência das espécies, o bem-estar humano e a produção de bens e serviços econômicos (MOTTA, 1997; MANGABEIRA; TÔSTO; ROMEIRO, 2011). A Millennium Ecosystem Assessment [MEA] (2005) classificou os serviços ecossistêmicos em quatro categorias: serviços de provisão ou de abastecimento, serviços de regulação, serviços culturais e serviços de suporte.

Para a gestão do capital natural, uma ferramenta é a valoração ambiental, que pode ser considerada uma área de fronteira das ciências econômicas, e trata-se da estimativa do valor monetário dos recursos naturais em relação aos outros bens e serviços disponíveis na economia (MOTTA, 1997). Esta ferramenta permite subsidiar a tomada de decisão em relação ao capital natural, subsidiando informações necessárias à eficiente gestão dos recursos naturais, e até mesmo propondo incentivos econômicos para sua preservação (ANDRADE et al. 2012).

Ao tratar da valoração ambiental, é importante distinguir dois termos importantes: as funções e os serviços ecossistêmicos. O valor das funções advém dos processos físicos, químicos e biológicos, por exemplo, como proteção do solo, estabilidade climática, oferta de habitat, entre outros, enquanto que os serviços ecossistêmicos dizem respeito aos benefícios, ao ambiente natural e para o ser humano, resultantes da interação com as funções ecossistêmicas. Deste modo, as funções do ecossistema são neutras de valor, enquanto seus serviços têm valor para a sociedade (MORAES; SAMPAIO; SEIDL, 2009).

\subsection{Histórico sobre a valoração ambiental e o uso e a ocupação do solo}

Liu (2007) realizou uma análise cronológica dos estudos relacionados à valoração dos serviços ecossistêmicos, em que constatou que estudos ganharam destaque sobretudo na década de 1960, com o surgimento de movimentos ambientalistas. Posteriormente, no início da década de 1990, mais atenção foi dada à importância da valoração ambiental, em virtude do acidente com o navio petroleiro Exxon Valdez, quando foram lançadas centenas de litros de petróleo no mar do Alasca nos Estados Unidos. Liu (2007) afirma que este evento gerou vários debates e estudos que pudessem produzir estimativas confiáveis o suficiente para ser o ponto de partida para a determinação judicial ou administrativa de danos aos recursos naturais - incluindo o valor de uso passivo perdido.

Entre os trabalhos frequentemente citados, cabe destacar o publicado por Costanza et al. (1997), publicado em conjunto com vários pesquisadores da área ecológica e econômica na 
Revista Nature, em 1997. Este trabalho foi um dos primeiros a realizar um levantamento global dos serviços ecossistêmicos providos pelos biomas em todos os continentes. Costanza et al. (1997) estimaram que o valor anual de 17 serviços ecossistêmicos para toda a biosfera era de US\$ 33 trilhões em valores da época. Outra importante contribuição na valoração dos serviços ecossistêmicos foi dada pela MEA (2005), que mobilizou mais de 1.300 cientistas ao redor do mundo, entre os anos de 2001 e 2005, cujo objetivo era reunir bases científicas para avaliar as consequências de alterações dos ecossistemas e aumentar a conservação e o uso sustentável desses em benefício do bem-estar humano. O The Economics of Ecosystems and Biodiversity [TEEB] (sigla em inglês para "A Economia dos Ecossistemas e da Biodiversidade") foi outra importante contribuição de larga escala no estudo dos serviços ecossistêmicos. Publicado em 2007 em Potsdam, na Alemanha, o estudo contou com mais de quinhentos pesquisadores ao redor do mundo, cujo objetivo principal era estimar os efeitos da perda global de biodiversidade e, assim, evidenciar os benefícios econômicos de sua conservação (ROMA et al., 2013).

Com ênfase na área de uso e ocupação do solo, Kreuter et al. (2001) utilizaram o LANDSAT MSS para quantificar as mudanças no uso da terra e nos serviços ecossistêmicos devido à expansão urbana no Condado de Bexar, no estado do Texas, Estados Unidos. Os autores analisaram a mudança na cobertura do solo entre os anos de 1976 e 1991 e estimaram os serviços ecossistêmicos em US\$ ha ${ }^{-1} \cdot$ ano $^{-1}$ de cada tipo de cobertura do solo. Em nível regional, no Brasil, alguns trabalhos vêm sendo realizados em bacias hidrográficas, como o trabalho de Andrade et al. (2012), em que realizaram a aplicação da valoração de serviços ecossistêmicos considerando a dinâmica de uso do solo da bacia hidrográfica dos rios Mogi-Guaçu e Pardo no estado de Estado de São Paulo, entre os anos de 2002 e 2012. Cunha et al. (2014) realizaram um estudo semelhante de valoração dos serviços ecossistêmicos no bioma Caatinga, no território bacia do Jacuípe, localizado no sertão do estado da Bahia.

As bacias hidrográficas são importantes espaços territoriais de gestão ambiental, principalmente dos recursos hídricos. É considerada como unidade básica para o planejamento e a gestão do ambiente natural e urbano da Política Nacional de Recursos Hídricos (Brasil, 1997). Esta subdivisão territorial permite realizar análise dos impactos da ação antrópica sobre as paisagens naturais e suas consequências sobre a dinâmica dos fluxos de serviços ecossistêmicos (ANDRADE et al. 2012). Desta forma, para Ross e Prette (1998), a gestão das bacias deve ir muito além dos recursos hídricos, contemplando outros componentes dos recursos naturais (solo, relevo, atmosfera, subsolo, fauna e flora).

Dada a importância territorial das bacias hidrográficas, faz-se necessário conhecer os impactos da mudança na cobertura do solo sobre os serviços ecossistêmicos nessa delimitação de área, além de entender a dinâmica de degradação dos serviços ecossistêmicos, mas também propor políticas ambientais eficazes de preservação (ANDRADE et al. 2012). A classificação de uso e ocupação do solo em bacias hidrográficas permite entender importantes variáveis ambientais, como tipo de solo, cobertura vegetal e recursos hídricos. Ajuda, ainda, a compreender a distribuição espacial e temporal das atividades humanas no território estudado, a planejar e orientar a ocupação da paisagem, respeitando sua capacidade de suporte ambiental (LEITE; ROSA, 2012).

As técnicas de sensoriamento remoto e geoprocessamento permitem obter de maneira rápida, confiável e repetitiva, em diferentes faixas espectrais e escalas, diversas informações sobre a superfície terrestre (ROSA, 2005). O reconhecimento de diferentes coberturas de solo 
é um dos principais objetivos do sensoriamento remoto. Esses procedimentos de distinção e identificação são chamados de classificação de imagens, podendo ser realizado de maneira manual ou automática, com o auxílio de técnicas de Processamento Digital de Imagens (PARANHOS FILHO; LASTORIA; TORRES, 2008). A classificação manual ou fotointerpretação de imagens é um método muito utilizado na interpretação visual de imagens de satélites, em que o operador utiliza a visão do olho humano e sua experiência para extrair informações destas imagens. Vasconcelos e Novo (2004) explicam que, embora a classificação manual seja mais precisa, ela pode se tornar inviável considerando o tamanho da área de estudo e a quantidade de informação para processar. A alternativa ao método manual é o uso de algoritmos computacionais para a classificação digital, embora os resultados não sejam satisfatórios, demandando um grande tempo de edição (VASCONCELOS; NOVO, 2004).

\subsection{Objetivo do estudo}

Diante do exposto, o objetivo deste trabalho é valorar os serviços ecossistêmicos na bacia do rio Santo Antônio, localizada no município de Guia Lopes da Laguna, por meio da análise de uso e ocupação do solo a partir dos coeficientes de valores dos serviços ecossistêmicos calculados por Costanza et al. (1997), por meio do uso de geotecnologias.

Com este estudo, pretende-se entender como a dinâmica do uso e da ocupação do solo tem modificado os serviços ecossistêmicos na bacia, servido como subsídio a gestores e tomadores de decisão, em uma área de interesse para a Rota de Integração Latino-Americana.

\section{METODOLOGIA}

\subsection{Delimitação e caracterização da área de estudo}

A bacia do rio Santo Antônio está localizada em uma área que abrange três municípios do Estado de Mato Grosso do Sul: Guia Lopes da Laguna, Maracaju e Ponta Porã; e pertence a sub-bacia do rio Miranda, localizada na bacia do rio Paraguai.

Conforme Abrão e Kuerten (2016), o rio Santo Antônio é o manancial responsável por todo o abastecimento público do município de Guia Lopes da Laguna. As principais nascentes do rio Santo Antônio estão localizadas na região da Serra de Maracaju, em cotas altimétricas que variam entre 600 e 630 metros.

Para a delimitação da bacia do rio Santo Antônio, foram utilizados, neste estudo, dados do Modelo Digital de Elevação TOPODATA, com resolução espacial de $30 \mathrm{~m}$ reamostrados, articulação 21S57_ZN (BRASIL, 2008). Foi utilizado, ainda, o software QGIS para processamento das informações da área de estudo. E com o auxílio do algoritmo "Channel network and drainage basins", do plug-in de processamento SAGA GIS, foi possível determinar o divisor de águas da bacia do rio Santo Antônio, totalizando uma área de 119.369,16 ha, conforme Figura 1. 
Figura 1 - Bacia hidrográfica do rio Santo Antônio

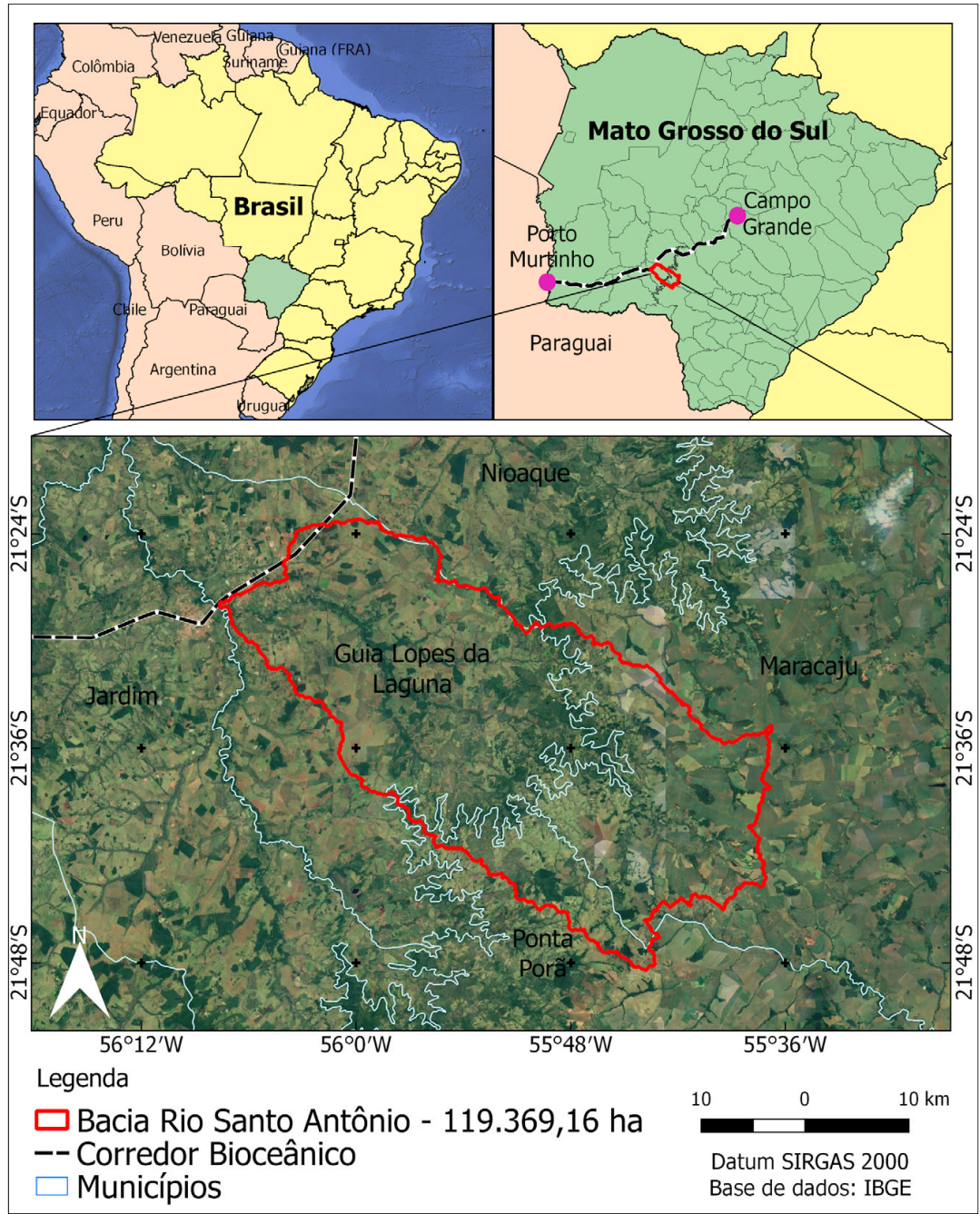

Fonte: Elaborado pelos autores.

\subsection{Identificação do uso e cobertura do solo}

Para identificar o uso e a cobertura do solo, foram utilizadas imagens do sensor Thematic Mapper (TM), a bordo do satélite Landsat 5 e imagens do sensor Operational Land Imager (OLI) a bordo do satélite Landsat 8, baixadas por meio da plataforma on-line Earth Explorer, do Serviço Geológico dos Estados Unidos (United States Geological Survey [USGS], sigla em inglês), exposto na Tabela 1. Para a confecção do mapa de uso e cobertura do solo, foram definidas quatro classes: Vegetação Nativa, Agricultura, Pastagem e Água.

Tabela 1 - Informação das imagens de satélite utilizadas no estudo

\begin{tabular}{ccc}
\hline Dado & Landsat 5/TM & Landsat 8/OLI \\
\hline Data & $12 / 06 / 2009$ & $10 / 07 / 2019$ \\
Órbita/Ponto & $225 / 75$ & $225 / 75$ \\
Resolução espacial (m) & 30 & 30 \\
Resolução radiométrica & 8 bits & 16 bits \\
Bandas & Bandas 4(R), 5(G), 3(B) & Bandas 5(R), 6(G), 4(B) \\
\hline
\end{tabular}

Fonte: United States Geological Survey [USGS] (2013). 
Foi aplicada a classificação automática supervisionada, aplicando-se o Modelo de Mistura Gaussiana, dada a sua facilidade, quantidade de parâmetros e precisão para descrição de grupamentos de amostras (SILVA, 2014). Segundo Paranhos Filho, Lastoria e Torres (2008), a Classificação Automática Supervisionada divide estatisticamente a imagem em classes baseadas em amostras de treinamento (ou áreas de treinamento) fornecidas pelo operador, de maneira que o sistema possa reconhecer padrões na imagem.

As áreas de treinamento foram coletadas diretamente em cada uma das imagens, haja vista a diferença de resolução radiométrica e espectral existente entre os dois sensores.

\subsection{Valoração de serviços ecossistêmicos}

Para valoração dos serviços ecossistêmicos, foi utilizada como referência a metodologia proposta por Kreuter et al. (2001) e testada por Andrade et al. (2012) e Cunha et al. (2014). Utilizaram-se como referência as estimativas dos serviços ecossistêmicos calculadas por Costanza et al. (1997).

Para obter valores dos serviços ecossistêmicos da bacia do rio Santo Antônio, foram utilizadas as classes de uso do solo identificadas na Tabela 2. Essas classes foram comparadas com os 16 biomas identificados no modelo de avaliação de serviços ecossistêmicos de Costanza et al. (1997).

Embora os tipos de uso e cobertura do solo desta pesquisa não sejam os mesmos utilizados por Costanza et al. (1997), os biomas mais representativos foram utilizados como proxy para a determinação do valor de cada categoria de cobertura do solo, como propôs Kreuter et al. (2001). A Tabela 2 indica a equivalência entre os biomas e as classes de uso e ocupação do solo identificados. Cabe destacar que o trabalho de Costanza et al. (1997) foi realizado considerando como moeda o dólar americano (US\$) no ano de 1994.

Tabela 2 - Classe de uso do solo e os biomas equivalentes na bacia do rio Santo Antônio

\begin{tabular}{ccc}
\hline Classes & Bioma equivalente & $\begin{array}{c}\text { Coeficiente dos serviços ecossistêmicos } \\
\left(\mathbf{U S} \mathbf{S} \cdot \mathbf{h a}^{-\mathbf{1}} \cdot \mathbf{a n o}^{-\mathbf{1}} \mathbf{)}\right.\end{array}$ \\
\hline Vegetação nativa & Tropical forest & 2.008 \\
Agricultura & Cropland & 92 \\
Pastagem & Grass/rangelands & 244 \\
Água & lakes/rivers & 8.498 \\
\hline
\end{tabular}

Fonte: Adaptado de Costanza et al. (1997).

O valor dos serviços ecossistêmicos de cada classe de uso do solo foi calculado pela Equação 1:

$$
\mathrm{VSE}_{\mathrm{tk}}=\mathrm{VC}_{\mathrm{k}} \cdot \mathrm{A}_{\mathrm{k}}
$$

Onde:

$\mathrm{VSE}_{\mathrm{tk}}=$ Valor total do serviço ecossistêmico estimado para a classe de uso do solo $\mathrm{k}$ $\left(\right.$ em US\$ $\cdot$ ano $\left.^{-1}\right) ; \mathrm{VC}_{\mathrm{k}}=$ Coeficiente para o serviço ecossistêmico correspondente à classe $\mathrm{k}$ (em US\$ $\left.\cdot \mathrm{ha}^{-1} \cdot \mathrm{ano}^{-1}\right) ; \mathrm{A}_{\mathrm{k}}=$ Área total da classe de uso do solo $\mathrm{k}$ (em ha).

Foi calculada, também, a contribuição do valor individual de cada serviço ecossistêmico 
por meio da Equação 2. Destaca-se que os serviços ecossistêmicos assumem diferentes valores para cada classe de uso do solo, de acordo com a Tabela 3.

$$
\mathrm{VSE} j=\Sigma\left(\mathrm{A}_{\mathrm{k}} \cdot \mathrm{VSE}_{\mathrm{k}}\right)
$$

Onde:

VSE $i=$ Valor da contribuição individual total do serviço ecossistêmico $j$, considerando todas as classes de uso do solo (US\$.ano ${ }^{-1}$ ); $\mathrm{A}_{\mathrm{k}}=$ Área da Classe de uso do solo $\mathrm{k}$ (em ha); $\mathrm{VSE}_{k}=$ Valor do serviço ecossistêmico correspondente à classe $K\left(\mathrm{em} \mathrm{US} \$ \cdot \mathrm{ha}^{-1} \cdot \mathrm{ano}^{-1}\right)$.

Tabela 3 - Valores individuais de serviços ecossistêmicos em US\$ $\cdot \mathrm{ha}^{-1} \cdot \mathrm{ano}^{-1}$

\begin{tabular}{ccccc}
\hline Serviços ecossistêmicos & Vegetação Nativa & Agricultura & Pastagem & Água \\
\hline Regulação de gás & $*$ & $*$ & 7 & $*$ \\
Regulação climática & 223 & $*$ & 0 & $*$ \\
Reg. de distúrbios & 5 & $*$ & $*$ & $*$ \\
Regulação de água & 6 & $*$ & 3 & 5.445 \\
Oferta de água & 8 & $*$ & $*$ & 2.117 \\
Controle da erosão & 245 & $*$ & 29 & $*$ \\
Formação do solo & 10 & $*$ & 1 & $*$ \\
Ciclagem de nutrientes & 922 & $*$ & $*$ & 665 \\
Tratamento de resíduos & 87 & $*$ & 87 & $*$ \\
Polinização & $*$ & 14 & 25 & $*$ \\
Controle biológico & $*$ & 24 & 23 & $*$ \\
Habitat/refúgio & $*$ & $* *$ & $*$ & 41 \\
Prod. de alimentos & 32 & 54 & 67 & $*$ \\
Matérias-primas & 315 & $*$ & $*$ & $*$ \\
Recursos genéticos & 41 & $*$ & 0 & 230 \\
Recreação & 112 & $* *$ & 2 & $*$ \\
Serviços culturais & 2 & $*$ & $*$ & $*$ \\
\hline Total & 2.008 & 92 & 244 & 8.498 \\
\hline
\end{tabular}

**Indica que o serviço ecossistêmico não é prestado pela respectiva categoria de uso do solo.

*Informação indisponível ou inexistente.

Fonte: Adaptado de Costanza et al. (1997). 
Figura 2 - Mapa de uso e ocupação do solo para os anos de 2009 e 2019, na bacia do rio Santo Antônio

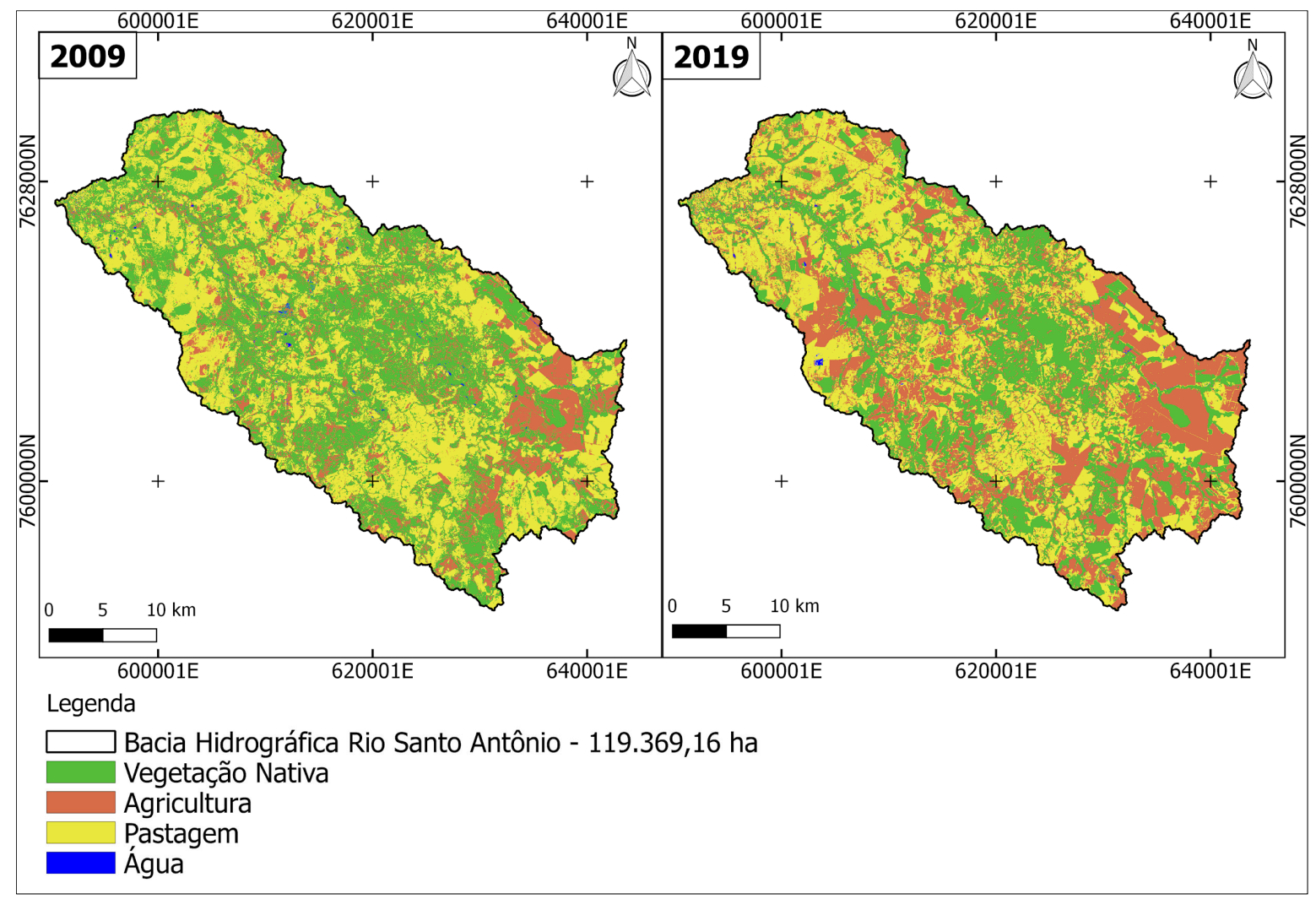

Fonte: Elaborado pelos autores.

\section{RESULTADOS E DISCUSSÃO}

\subsection{Classificação de uso e ocupação do solo}

Com a aplicação da classificação supervisionada, foi possível determinar as classes de uso e ocupação do solo para a bacia do rio Santo Antônio para os anos de 2009 e 2019, como apresentado na Figura 2. É possível identificar o aumento da classe Agricultura em relação às outras classes de uso do solo: Vegetação Nativa, Pastagem e Água. A Tabela 4 apresenta os resultados da classificação do uso e cobertura do solo na bacia do rio Santo Antônio.

Tabela 4 - Valores das classes de uso do solo na bacia do rio Santo Antônio entre os anos de 2009 e 2019

\begin{tabular}{c|c|c|c|c|c|c}
\hline Ano & \multicolumn{2}{|c|}{$\mathbf{2 0 0 9}$} & \multicolumn{2}{c|}{$\mathbf{2 0 1 9}$} & & \\
\hline \multirow{2}{*}{ Classe } & & Classe/Bacia & & Classe/Bacia & $\begin{array}{c}\text { Variação } \\
\mathbf{2 0 0 9 / 2 0 1 9}\end{array}$ & $\begin{array}{c}\text { Variação } \\
\mathbf{2 0 0 9 / 2 0 1 9}\end{array}$ \\
\hline & ha & $\mathbf{\%}$ & ha & $\mathbf{\%}$ & ha & $\mathbf{\%}$ \\
\hline Vegetação Nativa & 52123,59 & 43,67 & 38340,72 & 32,12 & $-13782,87$ & $-26,44$ \\
\hline Agricultura & 20380,05 & 17,07 & 39259,44 & 32,89 & 18879,39 & 92,64 \\
\hline Pastagem & 46490,67 & 38,95 & 41403,78 & 34,69 & $-5086,89$ & $-10,94$ \\
\hline Água & 374,85 & 0,31 & 365,22 & 0,31 & $-9,63$ & $-2,57$ \\
\hline Total & 119369,16 & 100,00 & 119369,16 & 100,00 & &
\end{tabular}

Fonte: Elaborado pelos autores. 
Observa-se que a classe de uso e ocupação do solo mais representativa no ano de 2009 foi "Vegetação Nativa", ocupando $43,67 \%$ da área total da bacia. Entretanto verificou-se que esta classe obteve a maior redução de área comparando-se 2009 e 2019, com um decréscimo de $26,44 \%$ de sua área, passando a ocupar 32,12\% da bacia.

Na classe "Agricultura", observou-se o maior acréscimo de área, com 92,64\% de incremento entre 2009 e 2019, praticamente duplicando a área ocupada, passando de 17,07\% para 32,89\% em termos de ocupação da bacia. As pastagens reduziram 10,94\% no período analisado, porém tornou-se a classe mais representativa em 2019, ocupando 34,69\% da área da bacia.

A classe de uso do solo denominada "Água", que representa os corpos hídricos, reduziu $2,57 \%$ no período analisado, embora este fato possa estar muito mais relacionado às condições climáticas da data em que as imagens de satélite foram capturadas do que, propriamente, à atividade antrópica.

\subsection{Valoração dos serviços ecossistêmicos}

Na Tabela 5, é apresentada a estimativa dos valores dos serviços ecossistêmicos na bacia do rio Santo Antônio para cada classe de uso e ocupação de solo analisada.

Tabela 5 - Estimativa dos serviços ecossistêmicos por classe de uso do solo na bacia do rio Santo Antônio, entre os anos de 2009 e 2019

\begin{tabular}{c|c|c|c|c|c|c|c}
\hline Ano & \multicolumn{3}{|c|}{$\mathbf{2 0 0 9}$} & \multicolumn{3}{c|}{$\mathbf{2 0 1 9}$} & \multicolumn{1}{c}{$\begin{array}{c}\text { Valor dos } \\
\text { Serviços } \\
\text { Classe }\end{array}$} \\
\hline & Área & $\begin{array}{c}\text { Valor dos } \\
\text { Serviços } \\
\text { Ecossistêmicos }\end{array}$ & & Área & $\begin{array}{c}\text { Variação } \\
\mathbf{2 0 0 9 / 2 0 1 9}\end{array}$ \\
\hline Vegetação Nativa & $52.123,59$ & $104.664 .168,72$ & 86,45 & $38.340,72$ & $76.988 .165,76$ & 82,07 & $-26,44$ \\
\hline Agricultura & $20.380,05$ & $1.874 .964,60$ & 1,55 & $39.259,44$ & $3.611 .868,48$ & 3,85 & 92,64 \\
\hline Pastagem & $46.490,67$ & $11.343 .723,48$ & 9,37 & $41.403,78$ & $10.102 .522,32$ & 10,77 & $-10,94$ \\
\hline Água & 374,85 & $3.185 .475,30$ & 2,63 & 365,22 & $3.103 .639,56$ & 3,31 & $-2,57$ \\
\hline Total & & $121.068 .332,10$ & 100,00 & & $93.806 .196,12$ & 100,00 & $-22,52$ \\
\hline
\end{tabular}

Fonte: Elaborado pelos autores.

Os resultados demonstraram que os serviços ecossistêmicos prestados pela bacia do rio Santo Antônio, considerando-se as classes de uso de solo no ano de 2009, correspondem a aproximadamente US\$ 121 milhões anuais, e, para o ano de 2019, esse fluxo correspondeu a aproximadamente US\$ 93,8 milhões por ano.

Em relação à classe de uso do solo "Vegetação Nativa", os maiores valores de serviços ecossistêmicos prestados, com aproximadamente US\$ 76 milhões por ano, representaram 82,07\% do valor total dos serviços prestados em 2019. Em seguida, tivemos a classe "Pastagem", com aproximadamente US\$ 10 milhões dos serviços prestados em 2019, o que representou 10,77\% do valor total. Estes resultados são semelhantes aos observados por Andrade et al. (2012), que constataram que os serviços ecossistêmicos prestados por áreas florestadas representaram cerca de $83 \%$ do total.

Embora a classe "Vegetação Nativa" seja a maior prestadora de serviços ecossistêmicos em termos monetários, observou-se que esta classe obteve uma redução de $26,44 \%$, a maior 
observada entre as classes estudadas. Este fato está relacionado à redução proporcional de vegetação nativa no período estudado. Em contrapartida, os serviços ecossistêmicos prestados pela classe "Agricultura" obtiveram a maior variação, com o aumento de 92,64\% do valor dos serviços prestados, resultado do aumento de área plantada no período.

De modo geral, constatou-se uma redução de 22,52\% no valor total dos serviços prestados pela bacia do rio Santo Antônio, o que corresponde a uma redução de aproximadamente US\$ 27,2 milhões por ano. A redução das áreas de Vegetação Nativa e Pastagem colaboraram significativamente para este resultado, dado o valor elevado associado a estas classes. No trabalho de Cunha et al. (2014), os autores constataram uma taxa de redução de 20,98\%, semelhante à observada neste estudo, embora tivessem utilizado apenas duas classes de uso de solo.

A Tabela 6 apresenta a contribuição individual dos 17 serviços ecossistêmicos na bacia do rio Santo Antônio, obtidos por meio da aplicação dos dados da Tabela 3, na Equação 2.

Tabela 6 - Estimativa individual dos serviços ecossistêmicos para a bacia do rio Santo Antônio, entre os anos de 2009 e 2019

\begin{tabular}{|c|c|c|}
\hline Serviços ecossistêmicos & Total 2009 (US\$.ha ${ }^{-1}$ ) & Total $2019\left(\right.$ US\$·ha $\left.{ }^{-1}\right)$ \\
\hline Regulação de gás & $325.434,69$ & $289.826,46$ \\
\hline Regulação climática & $11.623 .560,57$ & $8.549 .980,56$ \\
\hline Reg. de distúrbios & $260.617,95$ & $191.703,60$ \\
\hline Regulação de água & $2.493 .271,80$ & $2.342 .878,56$ \\
\hline Oferta de água & $1.210 .546,17$ & $1.079 .896,50$ \\
\hline Controle da erosão & $14.118 .508,98$ & 10.594.186,02 \\
\hline Formação do solo & $567.726,57$ & $424.810,98$ \\
\hline Ciclagem de nutrientes & $48.307 .225,23$ & $35.593 .015,14$ \\
\hline Tratamento de resíduos & $8.579 .440,62$ & $6.937 .771,50$ \\
\hline Polinização & $1.447 .587,45$ & $1.584 .726,66$ \\
\hline Controle biológico & $1.558 .406,61$ & $1.894 .513,50$ \\
\hline Habitat/refúgio & $15.368,85$ & $14.974,02$ \\
\hline Produção de alimentos & $5.883 .352,47$ & $6.120 .966,06$ \\
\hline Matérias-primas & $16.418 .930,85$ & $12.077 .326,80$ \\
\hline Recursos genéticos & $2.223 .282,69$ & $1.655 .970,12$ \\
\hline Recreação & $5.930 .823,42$ & $4.376 .968,20$ \\
\hline Serviços culturais & $104.247,18$ & $76.681,44$ \\
\hline
\end{tabular}

Fonte: Elaborado pelos autores.

Percebe-se que o serviço "ciclagem de nutrientes" apresentou os maiores valores anuais de serviços ecossistêmicos, cerca de US\$ 48,3 milhões em 2009 e US\$ 35,9 milhões em 2019, semelhante ao observado no trabalho de Cunha et al. (2014). Destacam-se os serviços "provisão de matéria-prima", "controle de erosão" e "regulação climática" como maiores valores monetários. Estes serviços possuem os maiores valores associados à classe vegetação nativa, portanto tendem a apresentar as maiores contribuições monetárias proporcionalmente ao tamanho desta classe.

$\mathrm{Na}$ análise de Andrade et al. (2012), resultados similares foram observados na bacia dos Rios Mogi-Guaçu e Pardo, onde foram identificados os cinco serviços ecossistêmicos mais relevantes 
em termos de valor: ciclagem de nutrientes, regulação de água, fornecimento de matérias-primas, produção de alimentos, controle da erosão. Já Sawut, Eziz e Tiyip (2013) identificaram que os três serviços ecossistêmicos mais relevantes no delta do rio Ugan-Kupa, localizado no noroeste chinês, corresponderam ao tratamento de resíduos, oferta de água e formação de solo, em razão das extensas áreas de pastagens desta região.

Ressalta-se que na metodologia utilizada neste trabalho a variação do valor anual dos serviços ecossistêmicos é diretamente proporcional à variação da ocupação do solo (área ocupada pela classe de uso do solo), uma vez que os coeficientes de serviços ecossistêmicos foram considerados estáticos ao longo do tempo.

Andrade et al. (2012) explicam que o cenário ideal para a valoração dos serviços ecossistêmicos deve levar em conta valores específicos para o local estudado e considerar a dinâmica ecológica, pois, na medida em que a oferta de um serviço ecossistêmico diminui, o seu valor tende a aumentar. Desta forma, a abordagem adotada neste estudo deve ser entendida como ordem de grandeza, utilizada como orientadora no debate entre a exploração e o uso sustentável dos recursos naturais.

\section{CONCLUSÃO}

Este estudo apresentou os resultados estimados da valoração dos serviços ecossistêmicos na bacia do rio Santo Antônio, um importante manancial de abastecimento do município de Guia Lopes da Laguna. Por meio da classificação supervisionada de imagens de satélite Landsat, foi possível identificar as classes de uso e ocupação do solo da área de estudo.

Conclui-se que há uma redução de $26,44 \%$ da área de vegetação nativa, bem como a migração de áreas de pastagem para agricultura, que, por sua vez, praticamente dobraram de tamanho entre 2009 e 2019, com um aumento de 92,64\%.

A vegetação nativa é classe de uso do solo que mais contribuiu monetariamente com os serviços ecossistêmicos na bacia estudada, devido à área total da classe e ao elevado valor dos serviços associados aos recursos florestais, totalizando cerca de US\$ 76 milhões anuais.

\section{AGRADECIMENTOS}

Os autores agradecem ao Ministério Público do Estado de Mato Grosso do Sul pelo apoio e pela disponibilização de recursos para a instalação do Centro Integrado de Proteção e Pesquisa Ambiental da Universidade Católica Dom Bosco (CEIPPAM/UCDB) e pela concessão de Bolsa de Estudo de Iniciação Científica e Mestrado no Programa de Pós-Graduação em Ciências Ambientais e Sustentabilidade Agropecuária da UCDB.

\section{REFERÊNCIAS}

ABRÃO, C. M. R.; KUERTEN, S. Avaliação da área de preservação permanente do rio Santo Antônio na colônia Santo Antônio em Guia Lopes da Laguna-MS: aplicação do novo código florestal. Boletim Goiano de Geografia, Goiânia, v. 36, n. 2, p. 265-84, maio/jul. 2016.

ANDRADE, D. C. Economia e meio ambiente: aspectos teóricos e metodológicos nas visões neoclássica e da economia ecológica. Leituras de Economia Política, Campinas, v. 14, p. 1-31, ago./dez. 2008.

INTERAÇÕES, Campo Grande, MS, v. 22, n. 3, p. 869-881, jul./set. 2021. 
ANDRADE, D. C.; ROMEIRO, A. R.; FASIABEN, M. C. R.; GARCIA, J. R. Dinâmica do uso do solo e valoração de serviços ecossistêmicos: notas de orientação para políticas ambientais. Desenvolvimento e Meio Ambiente, Curitiba, v. 25, p. 53-71, jan./jun. 2012.

BRASIL. Ministério da Ciência, Tecnologia e Inovações. Instituto Nacional de Pesquisas Espaciais (INPE). Topodata: banco de dados geomorfométricos do Brasil. TOPODATA INPE, São José dos Campos-SP, 2008. Disponível em: http://www.dsr.inpe.br/topodata. Acesso em: 30 abr. 2020.

BRASIL. Lei n. 9.433, de 8 de janeiro de 1997. Institui a Política Nacional de Recursos Hídricos. Diário Oficial da União, Brasília-DF, 8 jan. 1997. p. 470-74.

COSTANZA, R. et al. The value of the world's ecosystem services and natural capital. Nature, v. 387, n. 6630, p. 253-60, maio 1997.

CUNHA, F. L. S. J. Valoração dos serviços ecossistêmicos em bacias hidrográficas. 2008. 129 f. Tese (Doutorado em Desenvolvimento Econômico, Espaço e Meio Ambiente) -Universidade Estadual de Campinas, Campinas, SP, 2008.

CUNHA, J. U. C. P.; ANDRADE, D. C.; UEZU, A.; ALENCAR, C. M. M. Valoração econômica de serviços ecossistêmicos no território Bacia do Jacuípe (Bahia). Revista Debate Econômico, Cidade, v. 2, n. 2, p. 5-30, jul./dez. 2014.

KREUTER, U. P.; HARRIS, H. G.; MATLOCK, M. D.; LACEY, R. E. Change in ecosystem service values in the San Antonio area, Texas. Ecological Economics, [s.I.], v. 39, n. 3, p. 333-46, 2001.

LEITE, E. F.; ROSA, R. Análise do uso, ocupação e cobertura na bacia do rio Formiga, Tocantins. Observatorium: Revista Eletrônica de Geografia, Uberlândia, v. 4, n. 12, p. 90-106, dez. 2012.

LIU, S. Valuing ecosystem services: an ecological economic approach. 2007. 354 f. Dissertation (Doctor of Philosophy, specializing in Natural Resources) - University of Vermont, USA, 2007.

MANGABEIRA, J. A. C.; TÔSTO, S. G.; ROMEIRO, A. R. Valoração de serviços ecossistêmicos: estado da arte dos sistemas agroflorestais (SAFs). Campinas Embrapa Monitoramento por Satélite, 2011. 47 p.

MILLENNIUM ECOSYSTEM ASSESSMENT [MEA]. Ecosystems and human well-being: synthesis. Washington, D.C.: Island Press, 2005.

MORAES, A. S.; SAMPAIO, Y.; SEIDL, A. Quanto vale o Pantanal? Valoração ambiental aplicada ao bioma Pantanal. Corumbá: Embrapa Pantanal, 2010. 35 p.

MOTTA, R. S. Manual para valoração econômica de recursos ambientais. Brasília-DF: IPEA; MMA; PNUD; CNPq, 1997.

PARANHOS FILHO, A. C.; LASTORIA, G.; TORRES, T. G. Sensoriamento remoto ambiental aplicado: introdução às geotecnologias. 1. ed. Campo Grande: Editora UFMS, 2008. 198 p.

ROMA, J. C.; SACCARO JUNIOR, N. L.; MATION, L. F.; PAULSEN, S. S., VASCONCELLOS, P. G. A economia de ecossistemas e da biodiversidade no Brasil (TEEB Brasil): análise de lacunas. Rio de Janeiro: IPEA, 2013. 62 p. (Texto para discussão, 1912).

ROSA, R. Geotecnologias na geografia aplicada. Revista do Departamento de Geografia, São Paulo, v. 16, n. 16, p. 81-90, 2005. 
ROSS, J. L. S.; PRETTE, M. E. Recursos hídricos e as bacias hidrográficas: âncoras do planejamento e gestão ambiental. Revista do Departamento de Geografia, São Paulo, v. 12, n. 12, p. 89-121, 1998.

SAWUT, M.; EZIZ, M.; TIYIP, T. The effects of land-use change on ecosystem service value of desert oasis: a case study in Ugan-Kuqa River Delta Oasis, China. Canadian Journal of Soil Science, v. 93, n. 1, p. 99108, 2013.

SILVA, S. S. Segmentação de imagens utilizando combinação de modelos de mistura gaussianas. 2014. Dissertação (mestrado em Ciência da Computação) - Universidade Federal de Pernambuco, Recife, PE, 2014.

TÔSTO, S. G. Sustentabilidade e valoração de serviços ecossistêmicos no espaço rural do município de Araras, SP. 2010. Tese (doutorado em Desenvolvimento Econômico, Espaço e Meio Ambiente) - Universidade Estadual de Campinas, Campinas, SP, 2010.

United States Geological Survey [USGS]. USGS, 2013. Science for a changing world. Disponível em: http:// landsat.usgs.gov. Acesso em: 30 abril 2020.

VASCONCELOS, C. H.; NOVO, E. M. L. M. Mapeamento do uso e cobertura da terra a partir da segmentação e classificação de imagens: fração solo, sombra e vegetação derivadas do modelo linear de mistura aplicado a dados do sensor TM/Landsat5, na região do reservatório de Tucuruí, PA. Acta Amazonica, Cidade, v. 34, n. 3, p. 487-93, 2004.

\section{Sobre os autores:}

Wesley dos Santos Carvalho: Mestrando em Ciências Ambientais e Sustentabilidade Agropecuária pela Universidade Católica Dom Bosco (UCDB). Bolsista do Centro Integrado de Proteção e Pesquisa Ambiental (CEIPPAM). Engenheiro sanitarista e ambiental pela UCDB. E-mail: wesleysc352@gmail.com, Orcid: https://orcid.org/0000-0003-1244-893X

Monik Loraine Candido Cunha: Graduanda em Engenharia Sanitária e Ambiental pela Universidade Católica Dom Bosco (UCDB). Estagiária do Centro Integrado de Proteção e Pesquisa Ambiental (CEIPPAM). E-mail: ra176511@ucdb.br, Orcid: https://orcid.org/0000-0002-0293-2552

Izabella do Carmo Amaral: Graduanda em Engenharia Sanitária e Ambiental pela Universidade Católica Dom Bosco (UCDB). Estagiária do Centro Integrado de Proteção e Pesquisa Ambiental (CEIPPAM). E-mail: ra172175@ucdb.br, Orcid: https://orcid.org/0000-0003-4277-8307

Fernando Jorge Corrêa Magalhães Filho: Doutor em Saneamento Ambiental e Recursos Hídricos. Bolsista de produtividade pelo Conselho Nacional de Desenvolvimento Científico e Tecnológico (CNPq). Engenheiro sanitarista e ambiental. Professor e pesquisador na Universidade Católica Dom Bosco (UCDB). E-mail: fernandojcmf@hotmail.com, Orcid: http://orcid.org/0000-0001-5447-0137 
